\title{
Exploring Collaboration Technology Use: How Users' Perceptions Twist and Amend Reality
}

\author{
Alina Dulipovici \\ Dragos Vieru \\ alina.dulipovici@hec.ca \\ dragos.vieru@teluq.ca \\ To be published in Journal of Knowledge Management, vol.19, issue 4, 2015
}

\section{Structured Abstract:}

Purpose: This study examines how a collaboration technology is used by three organizational groups. The main focus is on the interplay between the users' perceptions (of the technology and of the knowledge shared) and the material properties of the collaboration technology.

Design/methodology/approach: Two theoretical frameworks (social representations and sociomaterial practice perspective) examine collaboration technology use to better understand the underlying dynamics. The research is conducted as a case study in an US company where a collaboration technology was being implemented.

Findings: The findings reveal a process model showing how social dynamics and users' perceptions of what the collaboration technology can do and cannot do to share the users' knowledge influence the users' behavior. Based on these perceptions, users will twist or amend their interpretation of the reality (the material properties of the technology) to justify their use of the collaboration technology. 
Research limitations/implications: This research is conducted as a single case study. However, the significant amount of time spent at the research site allowed for a very rich description of the events and processes involved.

Practical implications: This study offers guidelines on what influences use and adoption of collaboration technologies. It highlights the importance of providing more than just training as social dynamics and users' perceptions continuously influence the users' behaviour.

Originality/value: By combining two complementary theoretical frameworks, this study provides a novel and more in-depth explanation of collaboration technology use (or lack thereof).

Keywords: collaboration technology, knowledge sharing, social representation, sociomateriality, case study, IT use

Article Classification: Research paper

\section{Acknowledgments:}

The research was supported by a grant from the Social Sciences and Humanities Research Council, Ottawa, Canada 


\section{INTRODUCTION}

Collaboration tools are omnipresent in today's organizational environment, from email, text messaging, wikis and shared directories to sophisticated knowledge management systems and Web content management. These tools are used to support a variety of collaborative activities where users (also referred to as knowledge workers) across the whole organization connect and interact with each other or create, store, search and share information and knowledge. Business executives may find the benefits of collaboration tools alluring (Rozwell and Sussin, 2012), but a recent Gartner study (Landry, 2012) also observed "a great deal of confusion, hype and risk aversion" (p. 3 ) that keeps a significant number of organizations from pursuing IT-enabled collaborative initiatives. For the successful and effective use of inter- and intra-organizational collaboration technologies, organizations require not only successful deployment of the technology, but also - and this is, in fact, the more daunting part - cultural and behavioural changes leading to new work practices and new ways of thinking (Chi and Holsapple, 2005; Lee et al., 2012).

Seeking to better understand these technologies and their underpinnings, empirical research on various collaboration tools has received considerable attention over the past decades. An important stream of research (e.g., Brown et al., 2010; Paroutis and Al Saleh, 2009; Styhre et al., 2008; Sarker et al., 2005) has focused on the organizational factors leading to the adoption of collaboration technologies (e.g., technology characteristics, size, centralization, employees' participation, etc.). More recently, researchers have looked at the strategic alignment of collaboration technologies, specifically at the influence of organizational culture (Ravishankar et al., 2011; Rai, 2011; Burstein et al., 2010) and users' perceptions of the alignment process (Dulipovici and Robey, 2013). A key lesson from prior research is that collaboration tools need to satisfy many stakeholders and their use may have unexpected outcomes because the actual use of the technology depends upon three key aspects: 1) user perceptions and institutional factors; 2) material properties of the technology; and 3) the nature of knowledge shared (information vs. knowledge, tacit vs. explicit, individual vs. collective, etc.). Consequently, IT-based 
knowledge sharing is challenging because the specialization of each functional area renders organizational knowledge situational, cultural, and contextual (Boland Jr. and Tenkasi, 1995). Individuals do not necessarily use the same language, nor do they possess the same view of what needs to be shared and how it needs to be shared (what technology to use and how to use it) (Dulipovici and Robey, 2013). Notwithstanding the contributions of prior research, investigating collaboration technologies without considering all three aforementioned aspects is an important limitation. On one hand, general models of IT adoption (e.g., TAM or UTAUT [Venkatesh et al., 2003]) cannot be used as-is because they do not take into account the nature of the knowledge shared. On the other hand, most research on collaboration technologies has either left out users' perceptions (e.g., Gal et al., 2008; Jonsson et al., 2009) or the material properties of the technology (e.g., Dulipovici and Robey, 2013).

To fill this research gap, Brown et al. (2010) integrated theories from collaboration research and IT adoption and proposed a variance model to predict the intention to use and adopt a collaboration technology. This manuscript contributes to this research stream by further developing a model of IT use in the collaboration context. Specifically, this research objective is to examine how user perceptions of the collaboration technology, material properties of the collaboration technology, and the nature of knowledge influence usage. To do so, collaboration technology is examined as a "technology at work" (Orlikowski, 2007), where focus shifts from the impacts of technology to the dynamics that attach meaning to the newly implemented system and that stabilize its use within the existing organizational practices of knowledge sharing. In this context, the material (collaboration technology in an organizational context) and the social (knowledge workers) continuously create and re-create one another while knowledge workers socially negotiate their IT-enabled practices to share their knowledge. The main research question is: How do social and material dynamics influence practices of knowledge sharing and the use of a collaboration technology?

This research question is addressed by integrating two theoretical frameworks, social representation and sociomaterial practice perspective, which allow examining data from complementary angles to provide a 
more in-depth explanation based on three key aspects (user perceptions, material properties of the technology, and the nature of shared knowledge). The research site is a U.S. company providing IT consulting and technology deployment services and where a novel collaboration technology was being implemented.

The main contribution of this research is a process model explaining the dynamics of use for collaboration technologies. The model explains these dynamics at the group level; it shows how user perceptions about what the collaboration technology can do and about the knowledge to be shared shape negotiated practices of knowledge sharing, which ultimately influence IT adoption processes for the organizational groups studied. Social dynamics (e.g., training sessions, upper management's recommendations, and group leaders' opinions) will push users to continuously seek to align their perceptions of the collaborative tool with their actions. To do so, users will twist or amend their perception of the reality, namely of what the collaborative tool can and cannot do. First, this is an important takeaway for researchers and practitioners because it shows that, at the same time, social dynamics and users' perceptions simultaneously enable and constrain IT-based knowledge sharing practices. Second, it is argued that the process model is governed by the interplay between users' perceptions and the material properties of collaboration technologies.

The remainder of the paper is organized as follows: the next section presents the conceptual foundations of the study and the two theoretical frameworks. Then, the research methodology is described, followed by an analysis of the case data. A discussion of the findings and theoretical explanations follows. The last section concludes with the implications for research and practice. 


\section{THEORETICAL BACKGROUND}

\subsection{Studying collaboration technology use as subjective and adaptive}

Organizations are complex phenomena (Tsoukas and Chia, 2002). To study the IT impact on the individual, work practices, or the organization, some researchers have posited that the technology needs to be seen as a sort of "black box" that moves on a linear trajectory from invention to diffusion and adoption (Orlikowski and Iacono, 2001). This view has been strongly questioned in the last two decades by a variety of scholars (e.g., Orlikowski, 2010; Wagner et al., 2011; Leonardi, 2011) who have argued that such a perspective ignores the reciprocal influence between technology and its social context of emergence. This shift towards a social way of studying the relationship between IT and organization has two important consequences: that technologies are subjective and adaptive.

First, the social perspective contends that IT is subjective and bears within it traces of its social history. Individuals' thoughts about a technology are not formed in isolation but are based on collectively shared understandings of what the technology is or what it can do. In this sense, the social representation (SR) theory asserts that organizational actors create mental frameworks of references useful for the interpretation of reality (Moscovici, 1984). Through social interactions, social negotiation, or collective sensemaking, an individual's mental framework about a specific IT becomes part of his group's social representation for the purpose of behaving and communicating (Moscovici, 1984).

Second, individuals draw differently on their experience to transform and create different organizational patterns (Orlikowski, 2007). Thus, IT is an adaptive assemblage of a variety of material and human components (Vieru and Trudel, 2013). It assumes a practical meaning when it is used in a specifically situated social and material context (Wagner et al., 2011). The sociomaterial practice perspective (SPP) makes a distinctive move away from other theoretical frameworks, which look at either technology or human agency as a driver of change in structures and organizing. The main premise is that things, IT, people, and organizations do not have inherently established meanings, boundaries, or properties. The focus is on agencies that have intermingled with each other in such a way that their boundaries are 
dissolved (Orlikowski and Scott, 2008). Thus, researchers can focus on these entanglements to understand how their temporal meanings, boundaries, and properties are continually produced and reproduced.

The subjective and adaptive nature of IT use implies the need for a process theory that takes into consideration how different processes adapt and affect each other (Poole and Van de Ven, 2004). A process theory explains how a sequence of events that unfolds through time leads to some outcome, thus shedding light on how one micro-level event leads to and affects the ensuing one (Mohr, 1982). From this viewpoint, SR and SPP serve as theoretical foundations allowing us to identify the sequence of events, actions, and activities unfolding over time in a specific organizational context. Events, the main elements of the sequence, can be defined as being instances of social action relating to the IT adoption process. The resulting view of the process can tell a rich and detailed story of the events taking place within a target situation by explaining how influential conditions interact (such as user perceptions and institutional factors, IT functionality, and the nature of knowledge), how they collectively lead to future action, and what constrains them.

\subsection{Social Representations}

Socio-cognitive concepts such as sensemaking, technology frame of reference, narratives, or storytelling are theoretical frameworks commonly used in the IS literature to explain organizational change as the human agency exercised in social contexts, where "structures" may either impede or foster change. In the social psychology literature, there are other somewhat similar concepts: common sense, mediating structures, common knowledge, habitus, shared cognition, mental models, etc. The differences among all these concepts regard the level of analysis (some concepts are individual, others are group-level) as well as the main focus (the creation of meaning, the negotiation of meaning, the communication process, etc.). The concept of social representation is especially relevant for this study because it describes social issues in continuous evolution while taking into account the relationship between social construction (at the group level) and individual thought and behavior (Lahlou, 2001). 
Representations are cognitive structures that connect an individual to an object in a specific context. For example, a knowledge worker creates a representation of the collaboration technology to interpret what this technology is and what it does to support his knowledge-sharing practices. Faced with an unusual or unfamiliar object, an individual uses the representation (here, of the collaboration technology) to construct meanings, which make more sense to him. A representation is defined as "the ensemble of thoughts and feelings being expressed in verbal and overt behavior of actors which constitutes an object for a social group" (Wagner et al., 1999, p. 96). Thus, the representation is both the result of the constructed reality (the object being represented) and the cognitive process through which the representation is created and maintained in the individual's mind. To construct and reconstruct his representations, the individual draws on past experiences with technology (i.e., with the same technology and with technology in general), on his background, on his and his group's cultural values, and on his and his group's future goals and aspirations (Wagner et al., 1999). A group of individuals tends to form a common representation (or social representation) drawing on their individual representations (Moscovici, 1984). Thus, social representations not only help to interpret the reality, but also influence what the individuals say and how they behave within and across their social groups (Dulipovici and Robey, 2013). The creation of a representation is based on the processes of anchoring (naming and classifying novel objects according to an existing system of thought) and objectification (making the object tangible by associating images, material examples, or verbal metaphors) (Moscovici, 1984). For example, one knowledge worker cognitively represents the voicemail functionality of a collaboration technology based on known concepts from the same cognitive category (e.g., mail, voice, telephone voicemail service). This representation may be quite different from another knowledge worker's representation (e.g., voice message converted into text-based email in his inbox). Based on these initial representations, these two individuals will have difficulties understanding each other and their knowledge-sharing practices. Through social interactions, they gradually adjust their representations, specifically the objectification of the collaboration technology, to broaden their initial interpretation. In this sense, objectification drives the 
evolution of the representation; the representation and its corresponding behavior are adjusted almost simultaneously: "By acting on the world, I not only change it, I also change myself, and I recognize this change in myself and in the world" (Markova, 2000, p. 441).

When studying IT use in an organizational setting, a socio-cognitive approach such as SR explains actual use and why actual use is different from intended use during the period studied (Gal and Berente, 2008). The representations can reveal changes in the individuals' interests, priorities and work practices, which is particularly relevant for understanding the use of collaboration technologies. Therefore, representations provide interpretations that link individual action (use of the collaboration technology) to enabling structures (e.g., perceptions, beliefs and attitudes about the collaboration technology and the knowledge to be shared, norms and guidelines for sharing knowledge, norms and guidelines on how to use the collaboration technology) and their outcomes (e.g., IT-based practices of knowledge sharing). However, a social representation is a socio-cognitive concept and, as opposed to SPP, it does not take into consideration the material properties of IT and the underlying dynamics.

\subsection{Sociomaterial Practice Perspective}

The introduction of a new technology triggers a set of complex interactions. In particular, users' practical appropriation of a technology, which is strongly influenced by an organization's values and institutional characteristics, affects whether the "technology-in-use" becomes collaborative or not (Orlikowski, 2010). Thus, the characteristics of a specific technology do not fully determine its ability to produce collaboration. There is a dynamic process created by recursive interactions between the technology, human agency, and institutional norms and values. Emerging "sociomaterial" perspectives (Orlikowski, 2007, 2010; Mutch, 2013) focus on both social context and the materiality of the technological artifact and should be theorized as inextricably interrelated.

Sociomateriality represents a commitment to holding meaning and matter together in the conceptualization of technology (Orlikowski, 2010). Sociomaterial approaches draw special analytic attention to the materiality of technology, allowing researchers to investigate how the social and material 
intertwine to give shape to complex organizational structures and practices. Thus, two different sociomaterial approaches have emerged in the literature - agential realism and critical realism (Mutch, 2013) - and each highlights important aspects. Their main difference is that critical realism views the social and the material as separate entities put into association with one another but that become inseparable only through human agency occurring over time. In contrast, agential realism argues that the social is not separated from the material, and therefore there is only the sociomaterial as something that is already ingrained in the individual's perceptions of technology (Leonardi, 2013). In this view, a technology represents a sociomaterial assemblage (Orlikowski and Scott, 2008) that "emerges from practice and defines how to practice" (Wagner et al., 2010, p. 279). Here, practices are defined as “coordinated activities of individuals and groups in doing their 'real work' as they are informed by a particular organizational or group context" (Cook and Brown, 1999). In order to make sense of their practices, the sociomaterial assemblages reflect individuals' shared understandings within the organizational context (Orlikowski and Scott, 2008). Given the research objective to understand the agency shift between the material (IT) and the social (practices performed by the organizational members), this study adopts an agential realism approach.

Furthermore, technology is created based on the belief that a collection of practices (i.e., industry-based best practices) can be extrapolated from general to particular settings. According to SPP, the dynamic relationship between organizational actors and IT is reflected in practices and can be illustrated by two concepts: performativity and affordance. Performativity represents a dialectic process of resistance and accommodation that produces unpredictable reconfigurations of the sociomaterial assemblage (Wagner et al., 2010). In their analysis of an enterprise resource planning (ERP) implementation, Wagner et al. (2010) clarify the concept of performativity by comparing the differences between sociomaterial assemblages of the same IS to the differences between the games of American football and rugby. The American game of football emerged as a sociomaterial assemblage from the UK game of rugby when those playing the game altered over time the sociomaterial assemblage that it is now called rugby. The 
former is quite different from the latter in terms of rules, equipment, physical skills required for the athletes, and the discourse that surrounds the practice of the game. Thus, from the viewpoint of the SPP, professional-based communities tend to promote practices that have a local character based on an organizational, departmental, or goal-based context despite their engagement in the same shared practices (Knorr Cetina, 1999). This emphasizes the fact that there are always differences, even when organizational members are supposedly engaging in the same practices via the same technology.

In an organizational setting, IT artifacts are understood and appropriated in the context of specific practices (Orlikowski, 2007). Likewise, this study views technologies not only as a sum of their material functionalities but also in terms of the affordances they offer their users (Faraj and Azad, 2012). IT or system affordance represents the "potential for action that emerges out of the interrelationships among the technical features of a system, people's ability and predisposition to use these features in certain ways, and the organizational context within which this takes place" (Gal et al., 2014, p. 1372). Thus, affordances are neither an objective property of the technologies nor a subjective trait of the people who use them (Leonardi, 2013).

This study will not debate whether one of the two theoretical lenses - social representations or sociomateriality - provides more insights into technology adoption by individuals; the intent is to analyze empirical data based on a complementary use of these two perspectives in order to better illuminate our comprehension of the why and how of human agency. The following section details the methodological choices supporting the research question.

\section{METHODOLOGY}

This research is conducted as a case study in order to better understand the underlying dynamics of the phenomenon studied (Eisenhardt and Graebner, 2007). Given the research objective of this study, the first author spent a significant period of time at a deliberately chosen company in order to focus on the subjective descriptions of users' practices and their perceptions about their collaboration technology and 
their knowledge-sharing practices. The subjective and context-dependent nature of knowledge implies that interpretations of reality depend on individuals' thoughts and feelings and on other influences that may operate within the social context.

\subsection{Research site}

The research site (herein called IT Projects Authority, or ITPA) is a U.S. company providing IT consulting and technology deployment services to state agencies. Its role is to oversee and deploy governmental IT projects over $\$ 1$ million. ITPA was purposely chosen, first, because it was implementing a new collaboration technology, which was based on Microsoft Project Server combined with Microsoft SharePoint Server (hereafter Project/SharePoint). Second, the timing of this implementation was also important and, following the guidelines of other studies using representations, the authors managed to gain access just before the first go-live of the phased rollout. Finally, and most important, adopting Project/SharePoint at ITPA implies a major change, not only technologically, but also in terms of knowledge-sharing practices because ITPA members generally share their project experiences orally, by telephone or at meetings. The goal for the new system was to provide a unified and standardized platform for sharing knowledge about ongoing and completed projects. Therefore, Project/SharePoint was expected to replace the panoply of tools used at ITPA (e.g., telephone, shared drives, Microsoft SharePoint in a stand-alone version [hereafter SharePoint], email, instant messaging) to share information and knowledge about projects. With this new system, ITPA project teams can record project details, information about clients, and information about project management tools and methodologies. The system can also generate reports of aggregated data and provide access to project deliverables.

\subsection{Data collection}

Given the size of the company (500+ employees), data collection focuses on the individuals who work on a particular set of closely related IT projects regarding the deployment of a unified IT infrastructure for sharing data and information more efficiently. Furthermore, given ITPA's matrix structure, individuals 
working on these projects belong to three organizational groups: Group A (Project Planning), Group B (Operations), and Group C (Development). Following the traditions associated with the theoretical frameworks chosen, these three groups emerged during data collection as "natural groups" for the representation lens (Bauer and Gaskell, 1999) and as "fields of practice" for the SPP lens (Levina and Vaast, 2005). Project teams regularly needed to share knowledge within and across the three groups to sustain ITPA's expertise in IT project management and technology deployment.

Data collection lasted about six months. Given a major organizational restructuring that halted the implementation and adoption processes of Project/SharePoint, the authors decided to leave the field in order to protect the rich data already collected from this unrelated event, which could have significantly changed the individuals' representations. During the intensive time spent at ITPA's offices, 21 personal interviews and 5 group interviews (focusing on history, emergence, content, and usage of Project/SharePoint) were conducted with key informants (see Table 1). Non-participant observation (regular activities, meetings, and training sessions), reports, newsletters, and handouts from presentations provided data triangulation for the interviews. Thus, the final storyline for each group draws on multiple data sources and data collection methods.

Table 1 List of key informants

\begin{tabular}{|l|l|l|}
\hline \multicolumn{1}{|c|}{ Group A (Project planning) } & Group B (Operations) & \multicolumn{1}{c|}{ Group C (Development) } \\
\hline- 2 Program managers & -2 Project managers & -1 Section director \\
-1 Program lead & -2 Team members & -1 Lead architect \\
-1 Program coordinator & -1 Executive manager & -1 Business analyst \\
-2 Project managers & & -2 Team members \\
- 4 Team members & & \\
-1 Executive manager & & \\
\hline
\end{tabular}

\subsection{Data Analysis}

The first step of data analysis was the detailed coding of interview transcripts based on coding schemes reflecting constructs from the two theoretical frameworks and corresponding to the three key aspects of collaboration technologies: user perceptions, material properties of the technology, and the nature of the 
knowledge shared. The final refinement and validation of these codes resulted in the following codes for the SR framework: anchoring (drawing on common background, prior experience, organizational values, norms, goals), objectification (based on images, metaphors, and symbols), and description of knowledgesharing practices; the codes for the SPP framework focused on social interactions, differences in practices across groups, accommodations, demand for new practices, imposing new practices, negotiation of practices, signs of acceptance, and signs of resistance. Using NVivo, the interview data were analyzed in an iterative process by cycling between data and relevant literature (Eisenhardt and Graebner, 2007). The final set of codes formed the foundation for group narratives and for within- and cross-group analyses (across the three organizational groups studied). The next section first presents the group narratives and then the key concepts for each theoretical framework. For the social representation perspective, it reveals the group's cognitive aspects and their corresponding actions with regard to the collaboration technology and knowledge to be shared. For the social practice perspective, based on the key concepts of practice, performativity, and reconfiguration, it identifies episodes of resistance followed by negotiations from which the new IT was reconfigured to accommodate new practices.

\section{MAIN FINDINGS AND ANALYSIS}

\subsection{Group A (Project Planning)}

The majority of the Project Planning members are certified project managers (i.e., PMP ${ }^{\circledR}$ ) who speak highly of knowledge management and its role in IT projects. They are quick adopters of all the tools supporting knowledge sharing, but their use depends on previous experiences with these tools. Considering the variety of knowledge-sharing tools at their disposal (e.g., shared-drives, SharePoint, email, intranet), Group A members are rather dissatisfied with their knowledge-sharing practices: “People have the desire to share and they feel frustrated because they could do it better. [...] They feel that there is no platform or opportunity or place to share knowledge and make a difference" (Team Member \#2). The implementation of Project/SharePoint brought some excitement because the mandatory technical 
training showed them how the new collaboration system addresses most of the existing issues. Nevertheless, few people really use it, especially one of its main functions: managing project resources and budgets. Hence, required data is missing from the system and several reports cannot be generated automatically, as planned. After six months, Project/SharePoint is still not the main collaboration tool for Group A.

\subsubsection{SOCIAL REPRESENTATION PERSPECTIVE}

Cognition (Project/SharePoint): For this group, the members' backgrounds and previous experiences play an important role in the anchoring and objectification of their representations of the system and its knowledge-sharing practices. Some objectify Project/SharePoint based on their previous experience at another job: "Because of my background, I really got excited about the possibilities. So [I imagined] I would have this global entry point into the whole program, and then for each project I would have its own site with its own stuff. [...] It wouldn't be this one mess of documents [as is currently the case]" (Program Coordinator); or, at their current job: "One of the things we do is to capture dollars and hours. We kind of do it separately for each project; we don't tie this very closely. I think [Project/SharePoint] will get us there. It's a spot where we've never been before" (Team Member \#1). Social interactions and sensemaking at the training sessions help Group A members create a more precise objectification of the new system: "[Project/SharePoint] is supposed to provide a lot of details about the project and therefore automatically or magically pull it out for you so that everything is consistent. That is what we want. [...] I've seen the details in training about how it is supposed to work" (Team Member \#2).

Action (Project/SharePoint): The excitement felt by the members of this group does not translate into usage. If Project/SharePoint were to work its magic, everybody has to embark on it; if not, several reports cannot be generated. When the time came to transfer existing projects to Project/SharePoint, few individuals did it. In the words of Project Manager \#2: "Moving to [Project/ SharePoint] is a great thing. Prior to that, it's a lot of work." Thus, Program Manager \#1 expresses the group's opinion, saying that 
Project/SharePoint is "a fancy note-keeping program" that has to be used in parallel with email and the shared drives to support the group's activities.

Cognition (Nature of knowledge): The members of this group have various knowledge needs but they unanimously agree that they deal mostly with tacit knowledge about clients and IT projects: "We need input from those folks in operations, when we run into flags, so that we know what to do and what not to do again" (Program Manager \#1). For example, the program team does numerous PowerPoint presentations and distributes handouts to potential clients. When preparing the presentations, tacit knowledge about these clients and their preferences is usually unavailable: "Everything is in the people's heads and that's the problem. The knowledge is not documented; it is not shared, so it's lost" (Program Lead). Thus, group members assume (and objectify) that knowledge from previous projects is lost.

Project teams belonging to this group need to design and present potential solutions to potential clients. These tasks require thorough research on and analysis of the existing solutions. If faced with a similar problem, an existing solution could be reapplied, but the difficulty remains in assessing problems from the other projects. Documents created by other project teams "have their needs in mind. They don't have [name of Project Manager \#2's project] in mind," notes Project Manager \#2. Explicit knowledge is objectified as too specific and incomplete: "The documents were not created in a general way. [....] These documents tend to be very specific to that client or to the fact that they used this particular vendor" (Project Manager \#1).

Action (Nature of knowledge): Although most individuals perceive existing organizational knowledge as already "lost," their actions differ. Some recreate lost knowledge from the outset of their task, while others try searching for that rare pearl, but ultimately end up reinventing the wheel as well: "The observation that I have is that sometimes we reinvent the wheel" (Project Manager \#1).

\subsubsection{SOCIOMATERIAL PRACTICE PERSPECTIVE}

Resistance: At the start of the project, the mindset of group members reflects specific work norms as a result of the existence of a field-based set of practices. They want to share their knowledge, but they don't 
know how: “They're just now learning how to start working across departments. It's a challenge for a lot of people. They've never done this before and part of our role is to help them get through those challenges and understand the importance of working together outside of their silo and the benefit that they'll get from doing that" (Executive Manager). The evidence shows that various forms of resistance to adopting new knowledge-sharing practices surface during the implementation process: "Basically, the environment is 'this is your project. This is mine.' [....] If there is a defined need, yeah [another project team] may accommodate and inquire, but otherwise we don't share knowledge" (Program Lead). Replacing existing collaboration technologies and their corresponding practices is also a trigger for resistance: "We do share a lot of information. That is done very regularly here. [....] The question here is what tool to use and when to stop using it. Our people are open in terms of sharing but then, you know, they don't want to change how they do things" (Project Manager \#2).

Negotiation: Data analysis suggests that the goal of the negotiation process is to provide accommodations that would enable emergent sociomaterial assemblages. A representative from Group A approached an executive from Group B to negotiate integration of practices: "I had to shake hands with [the executive from Group B]. The idea was that when we have [a number of templates for our project deliverables] then we would talk to her and we would have a parallel summit of sorts to drive out [project management] standards" (Team Member \#3). The evidence also shows that negotiating continuously changes the sociomaterial assemblages: "[Initially] everybody agreed that we would classify all the PMBOK's deliverables by phase then, as a group or a team, we would identify which ones of those deliverables were essential to any projects. [....] Well, what happened is that [member A] got hers and [member B] has his templates and I got mine and [member C] got his and that kind of starts to fall apart. Now we're saying 'just keep doing what you're doing, but don't claim you got new standards"' (Team Member \#3).

Accommodation: Given the simultaneous presence of acceptance and resistance signs, practices are adjusted to integrate the use of Project/SharePoint with other tools already in place, especially with the 
shared drives: "There are Project/SharePoint folders and there are folders on the shared drives that [Group B] maintains and there are folders on the shared drives that [Group A] maintains" (Program Manager \#2). The new sociomaterial assemblages also involve integration of the new functionalities of the new system: "The structure [for the Project/SharePoint site] is created by the Project Management Office and everybody has to respect that. There are flexibilities also to add another section or to store an Excel document when the system was expecting a Word document. There is a flexibility involved in adding or modifying the usage. We can define our own usage as for example the contact lists. Contact lists may be used for email contacts or phone numbers but can be extended even to meetings" (Project Manager \#2).

\subsection{Group B (Operations)}

These members are seasoned project managers, with more than fifteen years of hands-on project management experience. However, their prior experience with collaboration technologies is limited. To share knowledge with the other groups, they prefer face-to-face meetings and telephone. As a result, existing collaboration tools are used ineffectively. However, Group B is excited about the idea that everyone from ITPA would embark on the same platform to share knowledge. Yet, after the training sessions, few members use it and hence the practices of this group do not change significantly. In the end, Project/SharePoint is not the main collaboration tool for Group B either.

\subsubsection{SOCIAL REPRESENTATION PERSPECTIVE}

Cognition (Project/SharePoint): Given the discrepancies in the members' backgrounds, objectification of the new collaboration system varies greatly. Some members from this group are eager to use it even if it requires less oral sharing and more documenting. Their objectification of the new system draws on the limitations of the shared drives, as explained by Team Member \#1: "My vision is that we take those things that everyone needs - standards, policies, procedures - we put them in a common library within [Project/SharePoint] that has some version control, access control, and an approval process. When I go 
look for a policy or standard, I know that the one I'm looking at is current, is approved, is the right version for me to see, and I have access to it. Right now, on the shared drive, that's not true." Despite this initial optimism, these members become skeptical after the training sessions, as explained by Project Manager \#2: "I think [Project/SharePoint] will help us, but a lot of times we rely on tools to do the work for us." After seeing a demo of the new knowledge-sharing practices imposed by Project/SharePoint, several members quickly adjust their representations of the new system, because they understand how different the new tool is in terms of work practices. Most important, they realize that they have to adopt new work practices proposed by the tool.

Other members objectify the use of the new system as "time consuming" compared to current practices. According to Project Manager \#1: “Going out and looking at somebody else's site and trying to go through that to see if there is something that I can use, I don't have time to do that. I'll go to that project manager and ask him."

Action (Project/SharePoint): Given top management's recommendation to use the system, some members use it for a few months before going back to their old practices. Others use a combination of old and new practices, albeit this combined approach is not what top management expects. For example, users store key project deliverables on Project/SharePoint, so that top management will think they are complying with their recommendation, but these project deliverables are not necessarily the most recent versions. Project Manager \#1 describes this practice: "To make sure that we are following the guidelines, the [Project/SharePoint] site is where everything is available. My upper team, that I report to, will go to the site and they will see what's going on. But I am still managing my resources on a more personal level, instead of relying on them to go to [Project/SharePoint] to pull things down."

Cognition (Nature of knowledge): The kind of knowledge the members of this group need to share concerns technical designs, technical architecture, statements of work, project schedules, status reports, and other project deliverables. According to Project Manager \#1: "Eighty-five to ninety percent of the of the knowledge is transferable and it eventually gets into documents." Specifically, documenting happens 
at the end of the project; until then, project knowledge is represented in relation to its source/author. Once this tacit knowledge is converted to documents, Project Manager \#2 believes it is very helpful even if the number of documents is overwhelming: "We got to the point where, as they were sending me the templates, I think what's happened is that it really scared me. I did not know anything about [the new project], you know; I mean it was just Oh My God! It part was overwhelming."

Action (Nature of knowledge): Group B members are consumers of their own documentation; therefore, they understand well the importance of having project documents and lessons learned to share. At the completion of a project, they document their tacit knowledge. However, there are significant discrepancies regarding what is documented, how well it is documented, and how accessible those documents are to others. Ultimately, most of them rely on personally contacting the author.

\subsubsection{SOCIOMATERIAL PRACTICE PERSPECTIVE}

Resistance: Group B's resistance is justified as a lack of time expressed in different forms: the time it takes to document ("Documenting takes a lot of time" - Executive Manager); time to document seen as less important than other activities ("I know that preparing documentation takes time from the project, but I do believe that [project teams] have to take care of documentation" - Team Member \#2); time to share documents ('I've got hundreds of files. If I had to upload them, it would take some time. Do they want to pay me to sit here and upload files to [Project/ SharePoint]?" - Project Manager \#1); and, time to search for documents ("I don't have time to look [at documents] while they're executing [a project] and I'm executing one" - Project Manager \#1). A collective belief regarding the best use of their time triggered group resistance to changes in existing knowledge-sharing practices. Therefore, misalignments between the practices imposed by the new collaboration system and the group's practices surfaced, and negotiation is necessary if the system is to be adopted by the group.

Negotiation: Data analysis suggests that a negotiation process ensued. Project/SharePoint is a voluntary system and its use is strongly encouraged by upper management. Some signs of acceptance of the new system reflect the group's willingness to collaborate: "We have spent millions of dollars in consultants 
and consultant fees to come in and help us develop processes, policies and procedures. [....] Why waste your time with a process or procedure, if you're not going to follow it? There's some resistance to that, but it's worth trying. That's where we're at. We're trying to sustain those efforts" (Team Member \#1).

Accommodation: While neither top management nor Group B members reach their preferred goals - the former to impose new practices and the latter to keep its old knowledge-sharing practices - the new sociomaterial arrangement gains enough support from both sides to reach a stable environment. The majority of the group that used the new system was used to reporting to upper management on key project deliverables. Yet, daily operations are managed and followed using individualized and personalized mechanisms such as face-to-face meetings and informal conversations.

\subsection{Group C (Development)}

Group $\mathrm{C}$ is responsible for developing, deploying, and supporting the technical side of all projects at ITPA. On a daily basis, group C members use the shared drive as their main tool to support their knowledge management activities; other tools, such as email, instant messaging, and web-based repositories for technical documents, are used for specific needs. Before the implementation of Project/SharePoint a SharePoint site had been set up for this group, but moving all documents from the shared drive is considered a low priority and the site is not used at all. The group's members had a strong identity that had been tied to their cultural norms of documenting and sharing technical knowledge: "It is the whole culture from square one: whatever we have we shared so that everyone [in our group] can get to it" (Lead Architect). Their use of the shared drive is extremely effective because they created their own organizing structure and their own system of version control. This effective use of the shared drive is also possible due to the small size of the group (approximately six people, plus external consultants who temporally join the team). Another reason is the opportunity for reuse, which is measured in dollars and time saved. Despite some favorable first impressions at the technical training sessions, Group C members ultimately decide not to adopt Project/SharePoint. 


\subsubsection{SOCIAL REPRESENTATION PERSPECTIVE}

Cognition (Project/SharePoint): Given their strong technical backgrounds and numerous similarities in terms of their previous experiences, the members of this group create representations that are highly consistent across their group. After the technical training, the new collaboration tool is perceived as a more organized and overt method for handling documents than the shared drive, as explained by the Lead Architect: "I think it's a good opportunity for better documentation and more visibility because we already know where to find documents on the [shared] drive but, with Project/SharePoint, we will force a methodology that will make it more visible to everybody else." Nevertheless, the two leaders of this group (the Section Director and the Lead Architect) also introduce the group to the objectification of Project/SharePoint as valuable, but taking too much effort for daily tasks and for transferring files from the shared drives: "A human can only do so much. To ask somebody to sit here to code all day long, to go to meetings, do project schedules, work with the customers and on top of everything do Project/SharePoint to make sure [the document] is in there, it's cumbersome" (Section Director).

Action (Project/SharePoint): Social interactions across groups and top management's directives regarding Project/SharePoint prove insufficient to instill any form of adjustment in the representations created by the members of this group. The leaders of the group, convinced that switching to Project/SharePoint is not worth the effort, see the transition as a low priority: "We have [Project/SharePoint]. We have a site but [Group C members] don't use it because that is one of the jobs of our business analyst, to move everything from the shared drives into [Project/ SharePoint]. He's not started yet" (Section Director).

Cognition (Nature of knowledge): All members of this team document a lot: "We need our documentation" (Section Director). A technical document is, therefore, objectified as an "opportunity for reuse" (Section Director). In the same vein, the Lead Architect refers to the knowledge of this group as "repeatable" and "standardized": "As the code is being written I want it to be analysed and pulled out to 
pieces to be useful again. I want standardized verification error, standardized handling of routines, standardized file I/O, that stuff."

Action (Nature of knowledge): For all members of this group, the actions are very clear - document: "So it is the last effort in a project. We signed off, we close, and we provide the deliverables and the documents" (Lead Architect). During the projects, the team meets regularly to share what is not documented yet: "We document a lot but we still need to meet and talk to ask for help from the team" (Business Analyst).

\subsubsection{SOCIOMATERIAL PRACTICE PERSPECTIVE}

Resistance: The evidence shows that, from the outset, clear resistance to any change in the current fieldbased practices emerged. After attending the mandatory technical training for Project/SharePoint, the members find the features of the new system useful. However, the group's perception is that managing the documents more effectively (at which Project/SharePoint is better than the shared drive) is not that important to them: "Everything that [Project/SharePoint] does, we can do it on the shared drive" (Business Analyst). The group feels that they document extensively but they need more help with documenting contextual knowledge, which generally is added in the form of comments or shared in meetings. Project/SharePoint's functionalities cannot support this need. Therefore, as long as the status quo can be maintained, the change is deemed too costly and time-consuming: "It's not reasonable for us; we're just not ready for it" (Section Director).

Negotiation: There were face-to-face meetings that could have provided the opportunity for trade-offs, but the leaders of this group refuse to use the new system for the time being: “... down the road, when things slow down, absolutely, it can be very valuable" (Section Director).

Accommodation: The negotiation's outcomes do not show any signs of acceptance of Project/ SharePoint. Group C continues to use the existing field-based practices of knowledge sharing: shared drive (within group) and email communications (across groups). 


\section{DISCUSSION}

This research investigates how social and material dynamics influence practices of knowledge sharing and the use of a collaboration technology. Table 2 shows a summary of the findings from the two theoretical perspectives used, SR and SPP. Three important themes emerge from these results.

Table 2 Summary of the findings regarding the use of a collaboration technology at ITPA

\begin{tabular}{|c|c|c|c|c|}
\hline & & Group A & Group B & Group C \\
\hline \multirow{2}{*}{ 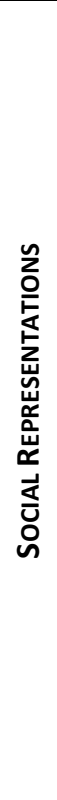 } & $\begin{array}{l}\text { Cognition } \\
\text { (Project/SharePoint } \\
\text { AND the nature of } \\
\text { knowledge) }\end{array}$ & $\begin{array}{l}\text { Influenced by members' } \\
\text { backgrounds and previous } \\
\text { experiences. } \\
\text { Technical training develops a } \\
\text { more precise representation of } \\
\text { Project/SharePoint. } \\
\text { Knowledge shared is mostly tacit. }\end{array}$ & $\begin{array}{l}\text { Influenced by a variety of } \\
\text { backgrounds and previous } \\
\text { experiences. } \\
\text { Technical training levels } \\
\text { the representations of the } \\
\text { tool (Project/SharePoint } \\
\text { not needed). } \\
\text { Knowledge shared is tacit } \\
\text { for ongoing projects and } \\
\text { explicit for completed } \\
\text { projects. }\end{array}$ & $\begin{array}{l}\text { Influenced by } \\
\text { members' backgrounds } \\
\text { and the group's } \\
\text { leaders. } \\
\text { Knowledge shared is } \\
\text { standard and } \\
\text { repeatable, mostly } \\
\text { explicit. }\end{array}$ \\
\hline & $\begin{array}{l}\text { Action } \\
\text { (Project/SharePoint } \\
\text { AND the nature of } \\
\text { knowledge) }\end{array}$ & $\begin{array}{l}\text { Parallel use with other } \\
\text { collaboration tools (data } \\
\text { conversion too difficult). } \\
\text { Most often, recreates the } \\
\text { knowledge, because knowledge is } \\
\text { lost, too specific, or incomplete. }\end{array}$ & $\begin{array}{l}\text { Parallel use with other } \\
\text { collaboration tools } \\
\text { (change of practices too } \\
\text { difficult). } \\
\text { Some documentation at } \\
\text { the end of the project, but } \\
\text { still relies on the authors. }\end{array}$ & $\begin{array}{l}\text { None (neither use of } \\
\text { Project/SharePoint, nor } \\
\text { of the new practices). } \\
\text { Document knowledge } \\
\text { to reuse and to share } \\
\text { contextual knowledge } \\
\text { in meetings. }\end{array}$ \\
\hline \multirow{3}{*}{ 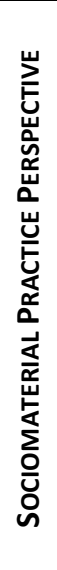 } & Resistance & $\begin{array}{l}\text { Various forms that target mainly } \\
\text { the new knowledge sharing } \\
\text { practices. }\end{array}$ & $\begin{array}{l}\text { Refusal to use the new } \\
\text { collaboration tool (time- } \\
\text { consuming). }\end{array}$ & $\begin{array}{l}\text { Refusal to use the new } \\
\text { collaboration tool } \\
\text { imposed by the group's } \\
\text { leaders. }\end{array}$ \\
\hline & Negotiation & $\begin{array}{l}\text { Informal bridges with other } \\
\text { groups so that knowledge sharing } \\
\text { can occur without adopting the } \\
\text { new practices; these bridges } \\
\text { prove to be ineffective. }\end{array}$ & $\begin{array}{l}\text { Needed due to } \\
\text { misalignment with top } \\
\text { management's } \\
\text { recommendation. }\end{array}$ & None. \\
\hline & Accommodation & $\begin{array}{l}\text { Parallel use with other } \\
\text { collaboration tools (mix of } \\
\text { existing and new practices). }\end{array}$ & $\begin{array}{l}\text { Parallel use with other } \\
\text { collaboration tools (mix of } \\
\text { existing and just a few new } \\
\text { practices). }\end{array}$ & $\begin{array}{l}\text { None (neither use of } \\
\text { Project/SharePoint nor } \\
\text { of the new practices). }\end{array}$ \\
\hline
\end{tabular}




\subsection{Theme 1: Influence of the groups' representations and social dynamics}

On one hand, all three groups appreciated the functionalities of Project/SharePoint. Members from Groups A and B even felt frustrated by having too many collaboration tools and were eager to change their knowledge-sharing practices. On the other hand, after Project/SharePoint was introduced, all three groups did not stop using the existing tools and did not adopt the new knowledge-sharing practices. Employing the lens of social representation allows us to explain this contradiction. First, analysis reveals that Project/SharePoint becomes associated with different images and meanings based mostly on the individual's past (background and previous experiences). From the outset, the anchoring and especially the objectification mechanisms led to the emergence of a cognitive interpretation of the constraints and affordances of the Project/SharePoint technology that barely varies within groups, but that varies greatly across groups. Furthermore, social dynamics during the mandatory technical training trigger adjustments to the existing representations because not only the benefits are better understood, but also the constraints, as is the case for Group B. The resulting representations influence individuals' perceptions about the functionality of the Project/SharePoint technology and justify their actions (Dulipovici and Robey, 2013) (i.e., different degrees of use for groups A and B and lack of use for group C).

Second, analysis reveals that users' perceptions about the technology are closely interwoven with users' perceptions about the nature of knowledge. Despite key social dynamics such as training sessions or the introduction of the advanced functionality offered by Project/SharePoint, representations about the nature of knowledge did not change during the investigation. This could be explained by the fact that the training sessions concerned technical aspects only, not the related work practices or the nature of knowledge. Hence, individuals from the three groups studied developed representations about the collaboration technology that were influenced not only by their backgrounds, previous experiences, and goals but also by their representations about the nature of their knowledge.

Taking into consideration the above arguments, the first research proposition is: 


\section{P1: Individuals' past, social dynamics, perceptions about the nature of knowledge to be shared,}

and perceptions of the collaboration tool itself will continuously influence their decision to use the tool and its knowledge-sharing practices.

\subsection{Theme 2: Perceptions of materiality}

Although the object of the representations is Project/SharePoint, the representations do not consider explicitly the constraints and affordances of the system. At the technical training, for example, all three groups saw demonstrations of the functionalities of Project/SharePoint. Nevertheless, use of Project/SharePoint does not improve consistently across the groups. A second analysis is necessary to evaluate the material aspects through the lens of the SPP.

The evidence suggests different forms of resistance regarding knowledge-sharing practices (Group A) and the general workload (Groups B and C). Negotiation is critical in order to introduce modifications or to keep the same sociomaterial assemblages. In all three groups, the concept of performativity clarifies how relationships between agents and technology are never fixed. Although the adoption process happens in the same organizational context and regards the same technology (Project/SharePoint), the resulting sociomaterial assemblages vary unpredictably across groups - from the complete refusal of any new knowledge-sharing practice (group $\mathrm{C}$ ) to the adoption of a mix of existing and new knowledge-sharing practices (group A); Group B's sociomaterial assemblages are somewhere between these two extremes. The common denominators of the three field-defined sociomaterial assemblages are their emergence from practices and their impact on the process of knowledge sharing. Thus, the SPP emphasizes the process, and assumes that practices are constantly changing even when agents are supposedly engaging in the same practice: "Pursuing the same thing necessarily produces something different" (Nicolini, 2007, p. 894). It also shows that system affordances can be enacted in different ways as they link up with the practices of different communities of users (Leonardi, 2013). However, these different enactments are influenced by the limits imposed by the SharePoint technology (material) configuration. At ITPA, top management defines the new knowledge-sharing practices by encoding document-sharing logics based on 
a specific organizational strategy. The findings suggest, on one hand, that significant differences exist among the three field-based practices in place, and between these practices and the practices imposed by the new collaboration tool, on the other hand. Existing sociomaterial assemblages based on common interests and field-based values are therefore at stake. While what the new technology is does not change during the implementation process, what changes is what the technology does. In all three groups performativity depends on the material properties of the collaboration technology, as well as on agents' perceptions of whether the new system affordances enable their ability to engage in effective knowledgesharing practices. This situation triggers resistance in all three groups that is followed by negotiations with the management. The resulting arrangements undermine the planned outcomes of the implantation project. Based on the above arguments, the second research proposition is:

P2: Materiality exists independent of agents, but materiality affordances do not; therefore, agents may perceive that a new collaboration technology offers few affordances for knowledge sharing, perceiving instead that it constraints their practices.

\subsection{Theme 3: Social representations and sociomaterial assemblages - twisting and amending reality}

The findings suggest that, for all three groups, agents' actions are formulated by their representations of what the collaboration technology can and cannot do and of how the knowledge can and cannot be shared (given its nature). For example, as described in the previous section, at the beginning of the implementation process, Group A members form a positive representation of the new tool based on their backgrounds, previous experiences, and their representations of the knowledge to be shared. Social dynamics such as technical training and social interactions among Group A members trigger adjustments to the initial representation of what the collaborative tool really has to offer. Thus, forms of resistance emerge as data conversion is considered too difficult and members barely use the tool. Social dynamics such as upper management's recommendation to use the tool, as well as the social representation about the nature of knowledge (which is perceived as too specific and incomplete), motivate Group A members 
to negotiate their practices with the other groups and to create informal bridges so that collaboration can occur. These actions trigger further adjustments of the representation about the material properties of the collaboration technology. This adjusted representation justifies the parallel use of the novel collaboration technology with other collaboration tools.

A similar trajectory can be described for Group B as well. Arrival of the new collaboration technology is met with excitement and skepticism as the social representation created draws on the members' backgrounds and their future goals. Social dynamics, such as technical training, and the social representation about the nature of the knowledge shared influence the evolution of the social representation about the material properties of the collaborative tool. Group B refuses to use the new tool, arguing that its usage is too time-consuming. Again, social dynamics, such as upper management's recommendation to use the tool, force Group B to look for solutions in order to realign their collaboration practices with upper management's recommendation. Their social representations about the knowledge to be shared and about the collaborative tool justify the group's combined use of the new collaborative tool with other tools.

Group C had a different but predictable trajectory, given their refusal to use the new collaborative tool. Despite some early signs of a positive social representation about the new collaborative tool and what it can do for the group, strong social dynamics created by the group's leaders convinced the group that it does not need the new tool. Even other social dynamics such as technical training sessions could not significantly change the group's representation about the new collaborative tool. Project/SharePoint is perceived as requiring too much effort and this representation justifies the group's complete refusal to use it.

By looking at the similarities among the three trajectories explained in the previous paragraphs, a process model for the use of collaboration technologies emerges. Specifically, all three groups establish a cognitive framework (the social representation) to interpret and evaluate the material properties of the new collaboration technology. Group actions (resistance/acceptance, negotiation, accommodation) are 
then the product of the interplay between social representations and social dynamics. As goal-driven organizational groups, each motivated by its own background, experience, goals and aspirations, they seem partially incompatible with ITPA's strategic objectives; the members of the three groups studied interact in an effort to impose their respective goals and forms of action (resistance, negotiation, accommodation, acceptance of practices, etc.). These agents shared a common set of practices within the same field of practice while pursuing a joint interest (Levina and Vaast, 2005). According to SPP, through practice, agents formalize their membership in a certain field and, at the same time, differentiate themselves from agents in other fields. Agents' actions and technology's materiality are distinct from one another, and it is only when they become assembled in specific ways that they can then create or recreate sociomaterial assemblages (Orlikowski, 2007). Thus, change of knowledge-sharing practices is driven by agents' actions, as they seek to negotiate their group practices of knowledge sharing and enact new sociomaterial assemblages (see Figure 1).

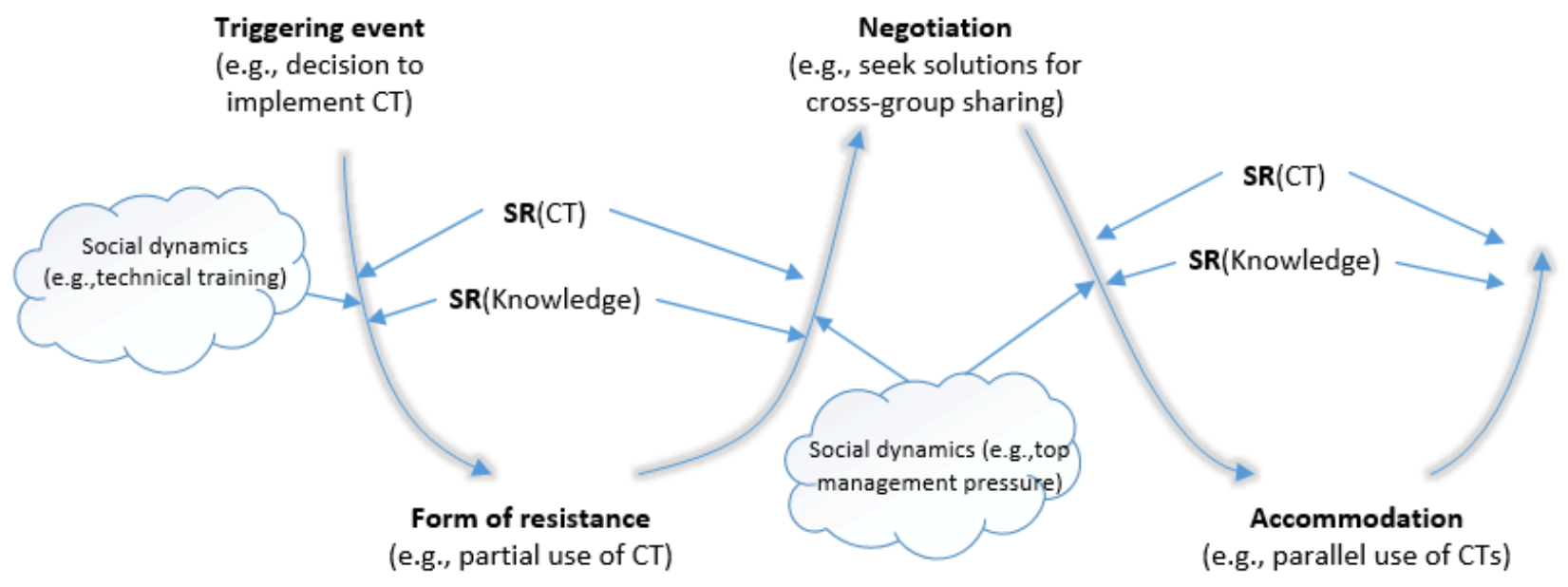

Figure 1: A process model for the use of collaboration technologies (CT)

Depending on whether they perceive that a technology affords or constrains their goals, agents twist or amend their interpretation of reality in order to link social and material agencies based on practices and norms defined by the group. 
Taking into consideration the above arguments, the third research proposition is:

P3: Social representations of technology and of the nature of knowledge corroborated through social dynamics will shape the process of use and adoption of a collaboration technology.

\section{CONCLUSIONS}

Despite their alluring usefulness and potential benefits, use of collaboration technologies in an organizational context cannot be taken for granted. Successful deployment of the technology is a necessary but insufficient premise (Chi and Holsapple, 2005; Lee et al., 2012). This research shows that social and material dynamics influence knowledge-sharing practices and therefore the use of a collaboration technology. These dynamics are explained based on data collected from an organization with intensive (IT and non-IT) collaboration practices. Focusing on three organizational groups, data analysis shows that agents' perceptions and corresponding actions are the main drivers of changes in knowledge-sharing practices. These actors seek to negotiate their group practices for knowledge sharing, and thus, they enact new sociomaterial assemblages (see Figure 1), twisting and amending the material properties of the collaboration tool.

\subsection{Limitations of the research and findings}

In order to provide a detailed explanation of how user perceptions, the material properties of the collaboration tool, and the nature of knowledge influence the use of the collaboration technology, the research was conducted as a single case study. Furthermore, data collection and data analysis focused on three organizational groups only. While these methodological choices may limit the results, the benefits of a deeper understanding of collaboration technology use surpass those of a generalizable variance model. Researchers can now use the process model proposed and test it in different organizational contexts to see how it holds when generalizability is the intended goal. 


\subsection{Implications for researchers and practitioners}

The main contribution of this article is to the literature on knowledge management and collaboration technologies. By proposing a process model, this study provides a more in-depth explanation, which improves our understanding of why the same collaboration technology is used differently across groups within the same organizational context. Although the case narratives had the same outsets and outcomes for both theoretical lenses, the dual approach offered different but complementary descriptions of the groups' dynamics during the adoption process. By using the socialmaterial practice perspective, it was found that practices are socially negotiated through processes of use, rather than being permanently selected at a particular moment in time. Focusing on negotiated practices - where IT materiality exists only in relation to potential users, so that collaboration technology features are always subject to users' representations - explains the different degrees of adoption. Consistent with the outcomes of other studies (Boudreau and Robey, 2005; Wagner et al., 2010), the ITPA's top management's expectation was that project managers use the new technology as-is, while the reality is that negotiated IT-based practices pushed the use toward a working and accepted collaboration technology. Therefore, the use of collaboration technologies represents a never-ending interplay fueled by a need to readjust representations of the collaboration technology and of the knowledge to be shared, and to negotiate the sociomaterial elements of work practices.

Knowledge management research drawing on socio-cognitive theories (sensemaking, technology frame of reference, narratives, etc.) has already examined the role of communication, improvisation, social interactions, and past experience as sources of collective sensemaking, which may ultimately affect the outcome of an organizational change (Weick, 1993). This study complements existing socio-cognitive studies in two ways. First, it examines both the emergence and the evolution of cognitive adjustments at the individual level and then make inferences (based on SPP as well), at the group level. Second, it grasps the combined effect of the individual's past experience and social dynamics, which translated into various objectifications of the collaboration technology and of the knowledge shared when using the new system, 
twisting reality (Group C) or amending it (Groups A and B). It is interesting to note that the objectification of the technology and the objectification of its content may be conflicting at times (Group A).

For practitioners, this study also suggests guidelines on what could influence use, adoption and ultimately success, thus complementing the guidelines offered by other studies (Chi and Holsapple, 2005). First, this study highlights the importance of user perceptions and their role in shaping user actions. To a certain extent, it doesn't really matter what functionality the technology offers, but how the users perceive its affordances. Second, as collaboration technology could enable and constrain knowledge-sharing practices, this case study showed the important role of key social events, such as training sessions or kickoff meetings, in shaping user's perceptions. For instance, training on new knowledge-sharing practices and on the skills required to share knowledge, as well as technical training with the collaboration technology, could lead to dynamic shifts in individuals' representations toward a group representation that is better aligned with top management's expectations.

\subsection{Possible areas for future research}

In addition to a generalizable description of the proposed process model, future research could further build on the IT-enabled organizational change literature in order to investigate adoption of collaboration technologies at the organizational level. What organizational and group-level mechanisms intervene and what reactions do they trigger that ultimately lead to the general adoption of the collaboration technology? A better understanding of these forces could allow practitioners to implement collaboration technologies with more realistic assumptions and expectations. 


\section{REFERENCES}

Bauer, M. \& Gaskell, G. (1999), "Towards a Paradigm for Research on Social Representations", Journal for the Theory of Social Behaviour, Vol. 29 No. 2, pp. 163-186.

Boland Jr., R. \& Tenkasi, R. (1995), "Perspective Making and Perspective Taking in Communities of Knowing", Organization Science, Vol. 6 No. 4, pp. 350-372.

Boudreau, M.-C. \& Robey, D. (2005), "Enacting Integrated Information Technology: A Human Agency Perspective", Organization Science, Vol. 16 No. 1, pp. 3-18.

Brown, S. A., Dennis, A. R. \& Venkatesh, V. (2010), "Predicting collaboration technology use: Integrating technology adoption and collaboration research", Journal of Management Information Systems, Vol. 27 No. 2, pp. 9-54.

Burstein, F., Sohal, S., Zyngier, S. \& Sohal, A. S. (2010), "Understanding of knowledge management roles and responsibilities: a study in the Australian context", Knowledge Management Research \& Practice, Vol. 8 No. 1, pp. 76-88.

Chi, L. \& Holsapple, C. W. (2005), "Understanding computer-mediated interorganizational collaboration: a model and framework", Journal of Knowledge Management, Vol. 9 No. 1, pp. 53-75.

Cook, S. \& Brown, J. S. (1999), "Bridging epistemologies: The generative dance between organizational knowledge and organizational knowing", Organization Science, Vol. 10 No. 4, pp. 381-400.

Dulipovici, A. \& Robey, D. (2013), "Strategic Alignment and Misalignment of Knowledge Management Systems: A Social Representation Perspective", Journal of Management Information Systems, Vol. 29 No. 4, pp. 103-126.

Eisenhardt, K. M. \& Graebner, M. E. (2007), "Theory Building from Cases: Opportunities and Challenges", Academy of Management Journal Vol. 50 No. 1, pp. 25-32.

Faraj, S. \& Azad, B. (2012), The materiality of technology: An affordance perspective. In: Leonardi, P. M., Nardi, B. A. \& Kallinikos, J. (eds.) Materiality and Organizing: Social Interaction in a Technological World. Oxford University Press.

Gal, U. \& Berente, N. (2008), "A social representations perspective on IS implementation: Rethinking the concept of frames", Information Technology \& People, Vol. 21 No. 2, pp. $133-154$.

Gal, U., Blegind Jensen, T. \& Lyytinen, K. (2014), "Identity Orientation, Social Exchange, and Information Technology Use in Interorganizational Collaborations", Organization Science, Vol. 25 No. 5, pp. 1372-1390. 
Gal, U., Lyytinen, K. \& Yoo, Y. (2008), "The dynamics of IT boundary objects, information infrastructures, and organisational identities: the introduction of 3D modelling technologies into the architecture, engineering, and construction industry", European Journal of Information Systems, Vol. 17 No. 3, pp. 290-304.

Jonsson, K., Holmström, J. \& Lyytinen, K. (2009), "Turn to the material: Remote diagnostics systems and new forms of boundary-spanning", Information and Organization, Vol. 19 No. 4, pp. 233-252

Knorr Cetina, K. (1999), Epistemic cultures: How the sciences make knowledge, Harvard University Press, Cambridge, MA.

Lahlou, S. (2001), Functional Aspects of Social Representation. In: Deaux, K. \& Philogene, G. (eds.) Representations of the Social: Bridging Theoretical perspectives. Basil Blackwell, New York.

Landry, S. (2012), Hype Cycle for Business Use of Social Technologies, 2012. Gartner inc.

Lee, S., Kim, B. G. \& Kim, H. (2012), "An integrated view of knowledge management for performance", Journal of Knowledge Management, Vol. 16 No. 2, pp. 183-203.

Leonardi, P. M. (2011), "When Flexible Routines Meet Flexible Technologies: Affordance, Constraint, and the Imbrication of Human and Material Agencies", MIS Quarterly, Vol. 35 No. 1, pp. 147-167.

Leonardi, P. M. (2013), "Theoretical foundations for the study of sociomateriality", Information and Organization, Vol. 23 No. 2, pp. 59-76.

Levina, N. \& Vaast, E. (2005), "The emergence of boundary spanning competence in practice: implications for implementation and use of information systems", MIS Quarterly, Vol. 29 No. 2, pp. 335-363.

Markova, I. (2000), "Amedee or How to Get Rid of It: Social Representations from a Dialogical Perspective", Culture Psychology, Vol. 6 No. 4, pp. 419-460.

Mohr, L. B. (1982), Approaches to explanation - variance theory and process theory. Explaining organizational behavior Jossey-Bass, San Francisco, CA.

Moscovici, S. (1984), The phenomenon of social representations. In: Farr, R. M. \& Moscovici, S. (eds.) Social representations: European studies in social psychology. Cambridge University Press, Cambridge.

Mutch, A. (2013), "Sociomateriality - Taking the wrong turning?", Information and Organization, Vol. 23 No. 1, pp. 28-40.

Nicolini, D. (2007), "Stretching Out and Expanding Medical Practices: The Case of Telemedicine", Human Relations, Vol. 60 No. 6, pp. 889-920. 
Orlikowski, W. (2007), "Sociomaterial Practices: Exploring Technology at Work", Organization Studies, Vol. 28 No. 9, pp. 1435-1448.

Orlikowski, W. (2010), "The sociomateriality of organisational life: considering technology in management research", Cambridge Journal of Economics, Vol. 34 No. 1, pp. 125-141.

Orlikowski, W. \& Iacono, S. (2001), "Research commentary: Desperately seeking "IT" in IT research - A call to theorizing the IT artifact", Information Systems Research, Vol. 12 No. 2, pp. 121.

Orlikowski, W. \& Scott, S. V. (2008), "Chapter 10: Sociomateriality: Challenging the Separation of Technology, Work and Organization", Academy of Management Annals, Vol. 2 No. 433-474.

Paroutis, S. \& Al Saleh, A. (2009), "Determinants of knowledge sharing using Web 2.0 technologies", Journal of Knowledge Management, Vol. 13 No. 4, pp. 52-63.

Poole, M. S. \& Van De Ven, A. H. (2004), Theories of Organizational Change and Innovation Processes. In: Poole, M. S. \& Van De Ven, A. H. (eds.) Handbook of Organizational Change and Innovation. Oxford University Press,, New York.

Rai, R. K. (2011), "Knowledge management and organizational culture: a theoretical integrative framework", Journal of Knowledge Management, Vol. 15 No. 5, pp. 779-801.

Ravishankar, M. N., Pan, S. L. \& Leidner, D. E. (2011), "Examining the Strategic Alignment and Implementation Success of a KMS: A Subculture-Based Multilevel Analysis", Information Systems Research, Vol. 22 No. 1, pp. 39-59.

Rozwell, C. \& Sussin, J. (2012), Business Gets Social Examples Highlight Adoption Trends and Key Performance Indicators. Gartner inc.

Sarker, S. V., Valacich, J. S. \& Sarker, S. (2005), "Technology adoption by groups: A valence perspective.", Journal of the Association for Information Systems, Vol. 6 No. 2, pp. 37-71.

Styhre, A., Ollila, S., Roth, J., Williamson, D. \& Berg, L. (2008), "Heedful interrelating, knowledge sharing, and new drug development", Journal of Knowledge Management, Vol. 12 No. 3, pp. 127-140.

Tsoukas, H. \& Chia, R. (2002), "On Organizational Becoming: Rethinking Organizational Change", Organization Science, Vol. 13 No. 5, pp. 567-582.

Venkatesh, V., Morris, M. G., Davis, G. B. \& Davis, F. D. (2003), "User Acceptance of Information Technology: Toward a Unified View", MIS Quarterly, Vol. 27 No. 3, pp. 425478. 
Vieru, D. \& Trudel, M.-C. (2013), "Unpredictable Reconfigurations: The Dilemma of the PostMerger Information Systems Integration", International Journal of Social \& Organizational Dynamics in Information Technology, Vol. 3 No. 1, pp. 47-60.

Wagner, E., Moll, J. \& Newell, S. (2011), "Accounting Logics, Reconfiguration of ERP Systems and the Emergence of New Accounting Practices: A Sociomaterial Perspective", Management Accounting Research, Vol. 22 No. 3, pp. 181-197.

Wagner, E., Newell, S. \& Piccoli, G. (2010), "Understanding Project Survival in an ES Environment: A Sociomaterial Practice Perspective", Journal of the Association for Information Systems, Vol. 11 No. 5, pp. 276-297.

Wagner, W., Duveen, G., Farr, R., Jovchelovitch, S., Lorenzi-Cioldi, F., Markova, I. \& Rose, D. (1999), "Theory and Method of Social Representations", Asian Journal of Social Psychology, Vol. 2 No. 1, pp. 95-125.

Weick, K. E. (1993), "The Collapse of Sensemaking in Organizations: The Mann Gulch Disaster", Administrative Science Quarterly, Vol. 38 No. 4, pp. 628. 